\title{
Optimized design and experiment of spiral-type intra-row weeding actuator for maize (Zea mays L.) planting
}

\author{
Honglei Jia ${ }^{1,2}$, Binglong $\mathrm{Gu}^{1,2}$, Zhongyang Ma ${ }^{1,2}$, Huili Liu ${ }^{1}$, Gang Wang ${ }^{1 *}$, \\ Mingwei $\mathrm{Li}^{1,2}$, Hewen $\operatorname{Tan}^{1,2}$ \\ (1. College of Biological and Agricultural Engineering, Jilin University, Changchun 130022, China; \\ 2. Key Laboratory of Bionic Engineering, Ministry of Education, Jilin University, Changchun 130022, China)
}

\begin{abstract}
Mechanical weeding not only avoids crop herbicide residue but also protects the ecological environment. Compared with mechanical inter-row weeding, mechanical intra-row weeding needs to avoid crop plants, which is conducive to causing a higher rate of seedling damage. In order to realize maize (Zea mays L.) intra-row weeding, a maize intra-row weeding mechanism was designed in this study. The mechanism can detect maize seedlings by infrared beam tube, then a sliding-cutting bevel tool moves spirally amid maize seedlings, so as to eradicate intra-row weeds. A field experiment was conducted under the following experimental conditions: the bevel tool rotation speed was 800-1400 r/min, the mechanism forward speed was $4-7 \mathrm{~km} / \mathrm{h}$, and the bevel tool depth was $2-14 \mathrm{~cm}$, the experimental results illustrated that the mechanism's average weeding rate and seedling damage rate were $95.8 \%$ and $0.6 \%$, respectively. The variance analysis showed that the primary and secondary factors that affecting the weeding rate and seedling damage rate were the same, which were bevel tool rotation speed, mechanism forward speed, bevel tool depth in soil in a descending order according to the significances. The result of the field experiment may provide a reference for intra-row weeding device design.
\end{abstract}

Keywords: optimization design, spiral forward, intra-row weeding actuator, maize planting

DOI: $10.25165 /$ j.ijabe.20211406.6542

Citation: Jia H L, Gu B L, Ma Z Y, Liu H L, Wang G, Li M W, et al. Optimized design and experiment of spiral-type intra-row weeding actuator for maize (Zea mays L.) planting. Int J Agric \& Biol Eng, 2021; 14(6): 54-60.

\section{Introduction}

In agricultural production, weeding crops can not only control weeds competing with crops for sunlight and nutrients, but also improve the soil properties and play a role in regulating soil fertility and water retention, etc. In addition, it can increase the air permeability of the soil and improve the nutrient supply of crop rhizomes, thereby promoting the growth and development of crop roots $^{[1]}$. During intertillage, weeds grow so vigorously as to easily compete with crops for fertilizer, sunshine, and water ${ }^{[2]}$. Weeding at this stage not only solves the problem that weeds and crops compete for nutrients, but also reduces plant diseases and insect pests caused by weeds, promotes crop growth, thus increasing yield and improving quality ${ }^{[3]}$. At present, crop weeding is mainly divided into manual weeding, mechanical weeding and chemical weeding. Manual weeding is not easy to be promoted on a large scale due to its low efficiency and tedious work ${ }^{[4-6]}$. Chemical weeding will not only damage the plants but also cause soil hardening after long-term use, which is adverse to plant growth.

Received date: 2021-02-23 Accepted date: 2021-10-07

Biographies: Honglei Jia, PhD, Professor, research interest: conservation tillage, Email: jiahl@vip.163.com; Binglong Gu, PhD candidate, research interest: intelligent weeding, Email: gubl18@mails.jlu.edu.cn; Zhongyang Ma, MS candidate, research interest: weeding among plants, Email: zyma20@ mails.jlu.edu.cn; Huili Liu, BA, Engineer, research interest: mechanical automatic control, Email: hlliu@mails.jlu.edu.cn; Mingwei Li, PhD candidate, research interest: intelligent agricultural machinery design, Email: 1mw271314@163.com; Hewen Tan, PhD candidate, research interest: maize harvest in the field, Email: tanhw@mails.jlu.edu.cn.

*Corresponding author: Gang Wang, $\mathrm{PhD}$, Associate Professor, research interest: intelligent agricultural field management machinery. College of Biological and Agricultural Engineering, Jilin University, Changchun 130022, China. Tel: +86-13166888540, Email: wangganggoodman@163.com.
At the same time, weeds in the field are easy to develop resistance, which will reduce the weeding rate. Mechanical weeding as the overall technology for sustainable development of agriculture has attracted increasing attention in recent years. The weeding machine can be divided into inter-row weeding machine and intra-row weeding machine. The weeding rate of inter-row weeding has reached $90 \%$, but there are few reports on intra-row weeding machines ${ }^{[7,8]}$. Moreover, the use of a machine for intra-row weeding often results in high seedling damage rates, so intra-row weeding operations at the current stage mainly depend on labor $^{[9-11]}$. At this stage, some weeding machines are being studied in the experimental stage. For example, Peruzzi et al. ${ }^{[12]}$ from Spain conducted research on automatic intra-row obstacle avoidance technology, using computer vision and GPS positioning technology to control precisely obstacle avoidance between plants, navigating through the KTR-GPS system to detect the plant position and control the trajectory of the end actuator between plants, thus allowing precise weeding. This method can effectively improve the weeding effect and reduce the seedling damage rate, but the cost is relatively high. Lee et al. ${ }^{[13,14]}$ from the USA developed an intra-row weeding robot for tomatoes with large planting spacing. It collects seedlings and weeds information in real-time through machine vision, makes analysis and conducts processing, and controls the robotic arm to spray the herbicide on the weeds, thus achieving the purpose of fixed-point weeding. Blasco et al. ${ }^{[15]}$ designed an inter-row weeding platform for low vegetable crops, which can locate the information of seedlings and weeds through two machine vision systems and release high voltage for electric weeding based on the end actuator. In addition to the above-mentioned methods for recognizing seedlings and weeds, many scholars have also gotten rid of dependence on intelligent navigation platforms. Zhou et al. ${ }^{[16]}$ 
used a cam-rocker-type swinging device to remove weeds between maize plants and used proximity switches to determine the position of maize plants, thereby removing weeds on the maize surface. Han et al. ${ }^{[17]}$ developed a comb component that rotates through a comb disc to realize weeding of the seedling belt. Niu et al. ${ }^{[18]}$ used the running trajectory of the wheel-type weeding device to weed between plants. Although a lot of researches on weeding have been carried out abroad, the number of actual application products is limited. Even the products in the experimental stage require human intervention to work.

In conclusion, the current studies mainly focus on low-rise crops or crops with large planting spacing. The intertillage period of rain-fed maize in Northeast China starts from late May to early September, which is a long time span. So it needs to perform weeding when plants are low, and also carry out intra-row weeding on taller maize plants ${ }^{[19]}$. At the same time, due to the phenomenon that the mechanical weeding components may be entangled and easily damaged, which is not conducive for machine vision-based mechanical weeding equipment to conduct vertical downward image acquisition. In this study, without relying on machine vision technology, a weeding actuator that recognizes plants through an infrared beam tube, and progresses spirally amid maize plants via a bevel tool was developed. It can assist mechanical weeding devices to complete intra-row maize weeding in intertillage period. It can be used not only for low crops, but also for high clearance weeding.

\section{Design of the weeding actuator}

\subsection{Introduction to infrared beam tube}

Active Infrared Intrusion Detectors, the full name of the infrared imaging tube, whose basic structure mainly consists of the transmitter, receiver, beam intensity indicator, optical lens, etc. The detection principle is to use the infrared rays emitted by the infrared light-emitting diodes for focused processing via the optical lens so that the light can be transmitted to a long distance and finally received by the photosensitive transistor. The part between the second node and the third node above the ground is equal to the internode $20-30 \mathrm{~cm}$ above the ground. The stalk is short and thick with fewer branches and leaves, which is easy to be used as an identification object. When an object blocks the infrared rays emitted by the transmitter, an alarm will be issued as the receiver cannot receive the infrared rays.

\subsection{Working principle of weeding actuator}

As shown in Figure 1 and Figure 2, when the power is turned on, the motor runs and drives the weeding machine to move forward in a spiral manner. The plant is identified by the infrared beam tube. When it encounters the plant, a feedback signal will be given to the control system. The control system controls the electric drive pusher to accelerate forward or backward. Under the combined action of the forward speed and the electric drive pusher, the end actuator moves forward in a spiral manner, thereby achieving intra-row weeding and seedling avoidance.

\section{Design and analysis of overall components}

\subsection{Weeding actuator}

The schematic diagram of the weeding actuator is shown in Figure 3. In order to realize left and right movement, the intra-row weeding actuator is connected with the machine through the slide rail. When the weeding actuator is connected with the machine and the spring is used to absorb the shock and maintain stability. In this study, it was found that the upper and lower axes slid at high speed if only connected by coupling, so bolts were added to the coupling for reinforcement.

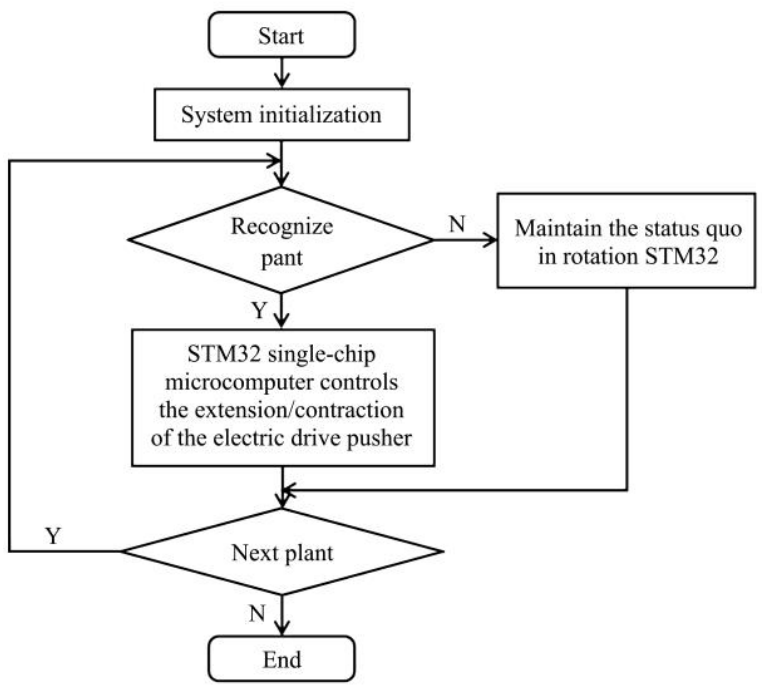

Figure 1 Flow chart of weeding and seedling avoidance program

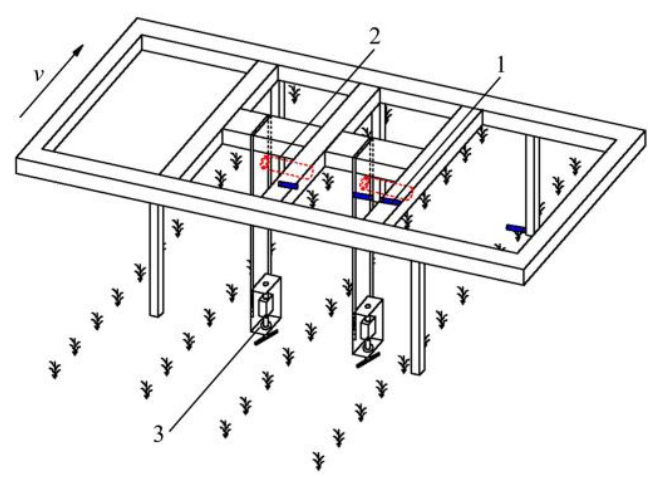

1. Infrared beam tube 2. Electric drive pusher 3 . Weeding actuator

Figure 2 Working principle diagram of weeding actuator

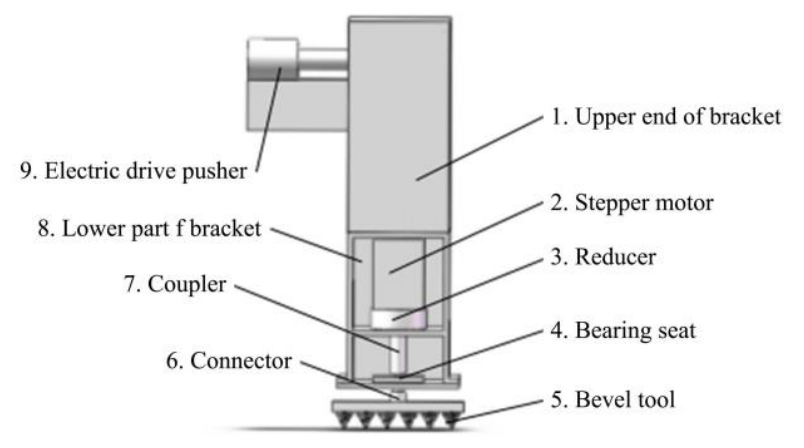

Figure 3 Schematic diagram of the weeding actuator structure

\subsection{Bevel tool design}

\subsubsection{Running trajectory design of the bevel tool}

To ensure that the weeding actuator moves freely between plants, the final trajectory with reference to the relevant structure is shown in Figure 4.

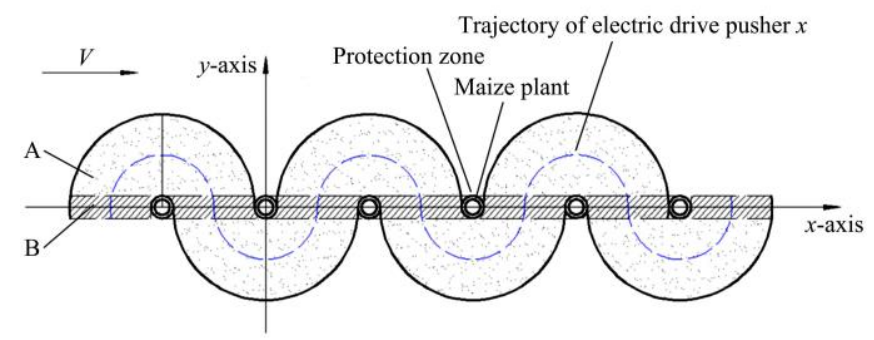

Note: A: Bevel tool path; B: Core intra-row weeding area of bevel tool.

Figure 4 Running trajectory of bevel tool 
To enable large weeding area as much as possible, this study adopted the largest weeding area in the calculation. The equation of the circle where the electric drive pusher trajectory was located at different stages is as follows:

$$
x^{2}+(y-12)^{2}=12^{2} \quad(0<x<12, y<0)
$$

where, $x$ means the distance that the weeding actuator travels in the direction of the machine; $y$ means the distance that the weeding actuator travels along the vertical direction of the tool.

$$
\begin{array}{ll}
(x-24)^{2}+(y-12)^{2}=12^{2} & (12<x<36, y>0) \\
(x-48)^{2}+(y-12)^{2}=12^{2} & (36<x<48, y<0)
\end{array}
$$

The electric drive pusher expands and contracts back and forth, presenting a periodic movement. The electric drive pusher can extend up to $24 \mathrm{~cm}$, which just makes the end actuator run from one end of the plant to the other end of the next plant. As the speed on the $x$-axis was set to $4 \mathrm{~km} / \mathrm{h}$, the operating speed of the electric drive pusher on the $y$-axis could be derived. The operating equation of each stage is as follows:

From Equation (4), it is derived that Equation (5).

$$
\begin{aligned}
& x^{2}+(y-12)^{2}=12^{2} \\
& y=12+\sqrt{12^{2}-x^{2}}
\end{aligned}
$$

From Equation (6), the result of derivation based on time $t$ is Equation (7).

$$
\begin{gathered}
x^{2}+(y-12)^{2}=12^{2} \\
v_{y}=-\frac{2 x v_{x}}{2(y-12)}=-\frac{x v_{x}}{y-12}
\end{gathered}
$$

Since Equations (8) and (9), there is Equation (10).

$$
\begin{gathered}
x=v_{x} \cdot t \\
y=12+\sqrt{12^{2}-\left(v_{x} t\right)^{2}} \\
v_{y 1}=-\frac{v_{x}^{2} \cdot t}{\sqrt{12^{2}-\left(v_{x} t\right)^{2}}}
\end{gathered}
$$

From Equation (11), it is derived that Equation (12).

$$
\begin{gathered}
(x-24)^{2}+(y-12)^{2}=12^{2} \\
v_{y 2}=-\frac{\left(v_{x}^{2} t-24 v_{x}\right)}{\sqrt{-v_{x}{ }^{2} t^{2}+48 v_{x} t-432}}
\end{gathered}
$$

From Equation (13), it is derived that Equation (14).

$$
\begin{gathered}
(x-48)^{2}+(y-12)^{2}=12^{2} \\
v_{y 3}=-\frac{v_{x}^{2} t-48 v_{x}}{\sqrt{-v_{x}^{2} t^{2}+80 v_{x} t-2160}}
\end{gathered}
$$

where, $v_{x}$ means the speed of the weeding actuator along the direction of the machine; $v_{y}$ means the speed of the weeding actuator along the vertical direction of the machine.; $t$ means the time the weeding actuator travels in the direction of the machine.

According to the moving speed and trajectory on the $x$-axis, the moving position of the weeding actuator on the $y$-axis can be judged. Equations (10), (12) and (14) represent the moving positions on the $y$-axis at different times, respectively.

\subsubsection{Sliding cutting curve design}

The Schematic diagram of the bevel tool structure is shown in Figure 5.

Since the cutting resistance decreases with the increase of the sliding cutting angle and increases with the increase of the friction angle, the sliding cutting resistance in ground breaking is less than the impact cutting resistance in ground breaking. As a result, the curved cutting edge of the sliding knife is more labor-saving than a straight one. According to the sliding cutting principle, the sliding cutting angle should be greater than the friction angle.
After the sliding knife enters the soil, it moves along the forward direction of the unit, and shear failure occurs when the soil interacts with the sliding knife. In this study, the cutting edge curve of the sliding knife was designed based on the parabolic function curve, which can ensure that the sliding cutting angle is greater than the friction angle so that it is convenient to control the cutting edge curve shape of the sliding knife and facilitate manufacturing. Supposing the sliding knife curve equation is

$$
y=a x^{2}+b
$$

As the constant term $b$ changes, the function position will change and its linearity will not change, so the constant $b$ was set to 0 in this work. The sliding knife curve starts at point $\mathrm{B}$ and ends at point $\mathrm{C}$, so the slope of the point on the curve can be calculated according to Equations (16) and (17). The vertical distance $l_{\mathrm{DC}}$ between the two points on the curve can be obtained from the coordinates, and the relational expression of constant $a$ can be obtained based on simultaneous Equation (18).

$$
\begin{gathered}
k_{1}=\tan \gamma_{1}=2 a x_{1} \\
k_{2}=\tan \gamma_{2}=2 a x_{2} \\
a=\frac{\left(\tan \gamma_{1}\right)^{2}-\left(\tan \gamma_{2}\right)^{2}}{4 l_{\mathrm{DC}}}
\end{gathered}
$$

Since the sliding cutting angle $\alpha_{1}, \alpha_{2}$ and $\gamma_{1}, \gamma_{2}$ of the sliding knife are complementary angles, the final sliding knife curve equation can be obtained as follows:

$$
y=\frac{\left[\tan \left(90^{\circ}-\alpha_{1}\right)\right]^{2}-\left[\tan \left(90^{\circ}-\alpha_{2}\right)\right]^{2}}{4 l_{\mathrm{DC}}}
$$

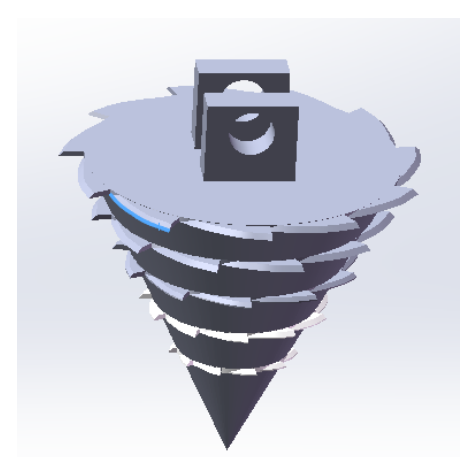

a. Front view of taper cutter

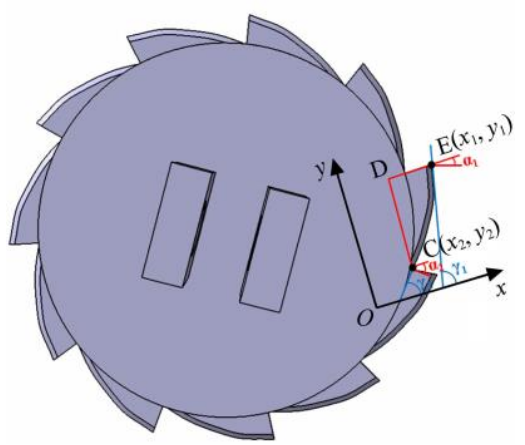

Note: $\alpha_{1}$ means the initial slip angle; $\alpha_{2}$ means the end slip angle; $l_{\text {DC }}$ means the height of a single blade

b. Vertical view of tapered cutter

Figure 5 Schematic diagram of bevel tool structure

\subsubsection{Establishment of sliding cutting angle}

The curve equation of the sliding cutting angle of the sliding knife was obtained from the above analysis. The shape of the sliding knife curve was determined by the three parameters $\alpha_{1}, \alpha_{2}$, and $l_{\mathrm{DC}}$. As can be seen from Figure 4 , the sliding angle is progressively increasing, namely $\alpha_{2}>\alpha_{1}$. In order to meet the 
sliding cutting condition, the initial sliding cutting angle $\alpha_{1}$ should be greater than the friction angle $\varphi_{0}$, so let the friction angle be $20^{\circ}$, then $\alpha_{1}>20^{\circ} . \quad \alpha_{1}$ and $\alpha_{2}$ are complementary angles, namely $\alpha_{2}<70^{\circ}$, so the value range of the end sliding cutting angle $\alpha_{2}$ is $20^{\circ}<\alpha_{2}<70^{\circ}$. When the sliding cutting angle is $45^{\circ}$, the sliding cutting effect is the best, if it exceeds $45^{\circ}$, the sliding cutting effect gradually weakens, so the sliding cutting angle $\alpha$ is controlled between $20^{\circ}-45^{\circ}$. When the height of the sliding knife $l_{\mathrm{DC}}$ is constant, different sliding knife curves will be obtained by changing the sliding cutting angle.

\section{Weeding actuator control system}

The structure diagram of the weeding actuator designed in this study is shown in Figure 6. The speed ratio of the reducer was 6:1 in the system. The implementation system of intra-row weeding was built by combining hardware and software.

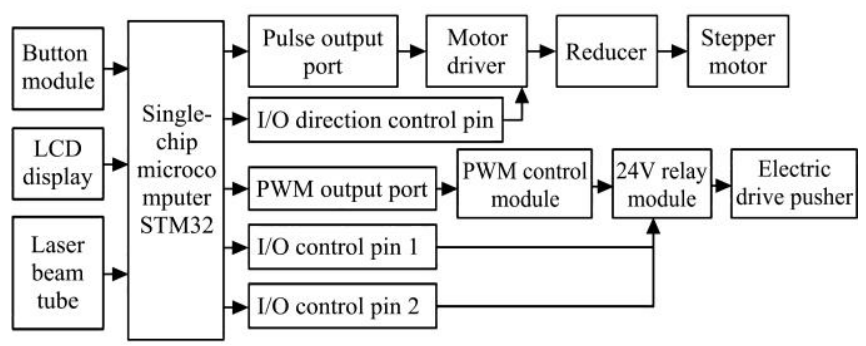

Figure 6 System structure block diagram of weeding actuator

\subsection{System hardware design}

The automatic weeding system serves as the monitoring and control center of the weeding end actuator. It can control the extension or contraction of the Linear Actuator in real-time by collecting the signal of the infrared beam sensor, so as to realize the function of adaptive avoidance of plants. The system consisted of a power conversion circuit, motor drive module, STM32F103C8T6 chip, clock circuit, reset circuit, key module, liquid crystal display (LCD) module, program download circuit, signal acquisition circuit and electric drive pusher control circuit.

The clock circuit consisted of an $8 \mathrm{MHz}$ crystal oscillator and two $20 \mathrm{pF}$ capacitors, which can provide a stable clock source for the single-chip microcomputer; the reset circuit was a circuit device used to restore the circuit to its initial state, and the main function was to achieve a power-on reset. The module P3 of the LCD screen display adopted a serial communication mode. The module of serial and parallel modes was controlled by the PSB port. When grounded, it is serial communication, and the display function can be realized merely by connecting the three pins of R/W, EN and RS. U4 CH340G chip is a USB bus transfer chip that converts the USB signal into a serial port signal to realize the program download function of the STM32 single-chip microcomputer. The electric drive pusher control circuit consisted of two $24 \mathrm{~V}$ relays and a PWM control module, where the PWM control module enlarged the PWM signal output by the single-chip microcomputer, thereby controlling a larger-power electric drive pusher; the two relays control the high and low levels of two I/O ports of the single-chip microcomputer, Con1 and Con2, to realize opening and closing, thereby controlling the extension and contraction of the electric drive pusher. Using the laser beam tube, the signal acquisition circuit converted the $5 \mathrm{~V}$ voltage output into a $3 \mathrm{~V}$ voltage that can be received by the single-chip microcomputer through a voltage divider circuit so as to realize the acquisition of the interrupt signal.

\subsection{System software design}

Figure 7 shows the block diagram of the system software flow. First, the system was initialized to complete the initialization of STM32 clock, I/O pin register, LCD display module, timer and so on. The button module was adopted to set the extension or contraction speed of the electric drive pusher under different operating speeds of the machine. Then the machine started to move forward, while the system started to operate. LCD displayed information such as the stepper motor speed, the total weeding plants and the operating speed of the electric drive pusher. STM32 single-chip microcomputer controls the uniform rotation of the stepper motor through pulse modulation to realize the rotary weeding operation. A laser beam tube was used to monitor whether there were plants. When there were plants, the single-chip microcomputer used PWM pulse width modulation signal and high and low levels of the I/O to control the module of PWM control and relay to realize the speed regulation and extension or contraction of the electric drive pusher, so as to complete S-shaped weeding operation between the gaps of the plants.

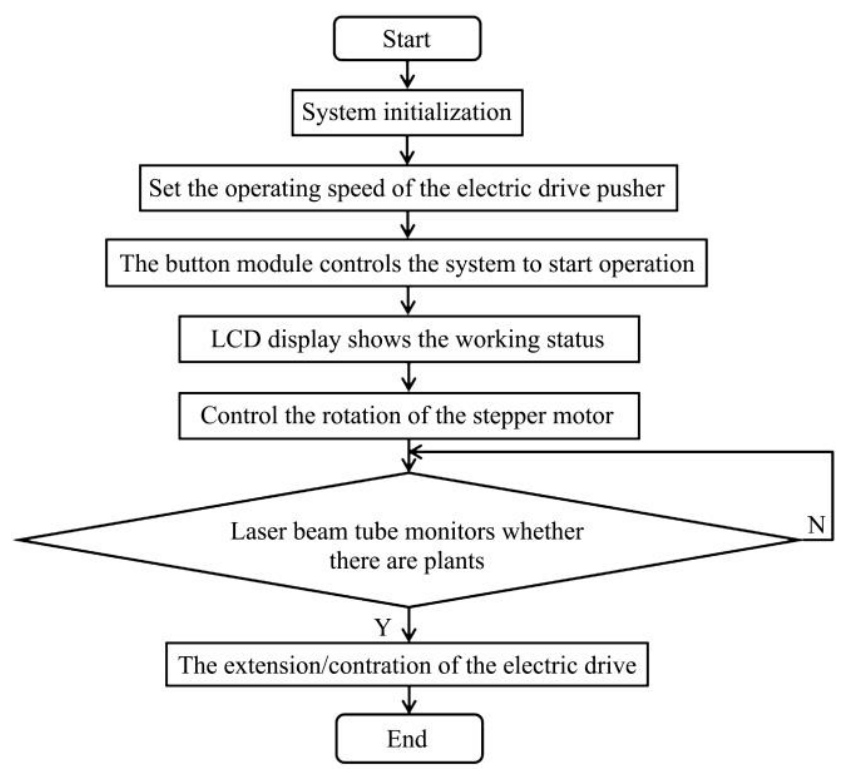

Figure 7 System software flow diagram of weeding actuator

\section{Field experiments}

\subsection{Test conditions}

The experiment was conducted from October 21 to October 28, 2019, at the test site of CAAMS Menoble Co., Ltd., Gu'an, Hebei $\left(116^{\circ} 17^{\mathrm{E}} \mathrm{E}, 39^{\circ} 19^{\prime} \mathrm{N}\right)$. The maize variety was xianyu 335 in the test site. The soil firmness was $543.5 \mathrm{kPa}$, the average height of the maize plant was $130 \mathrm{~cm}$, and the machine was powered by the high clearance chassis of Shandong Rizhao Wuzheng Group, with a power of $129 \mathrm{~kW}$. During the experiment, the temperature of the outdoor was $6^{\circ} \mathrm{C}-18^{\circ} \mathrm{C}$, the inter-row spacing of maize was 54$67 \mathrm{~cm}$, and the intra-row spacing of maize was 18-36 cm. Multiple group tests were conducted in the test site, with field experiments and operation results shown in Figure 8.

\subsection{Experimental design}

Based on previous research of the research group and the experience of soil bin experiments, and under the premise of determining the cone angle parameters of the bevel tool of the intra-row maize weeding mechanism structure, the bevel tool speed, the mechanism forward speed, and the bevel tool depth in soil were 
determined as the three main working parameters that affect the weeding performance of the weeding mechanism ${ }^{[20-22]}$. A three-factor four-level orthogonal test was carried out with the bevel tool speed, the mechanism forward speed, and the bevel tool depth in soil as the test factors, and with the weeding rate and the seedling damage rate were used as experiment indexes. The test factors and levels are shown in Table 1.

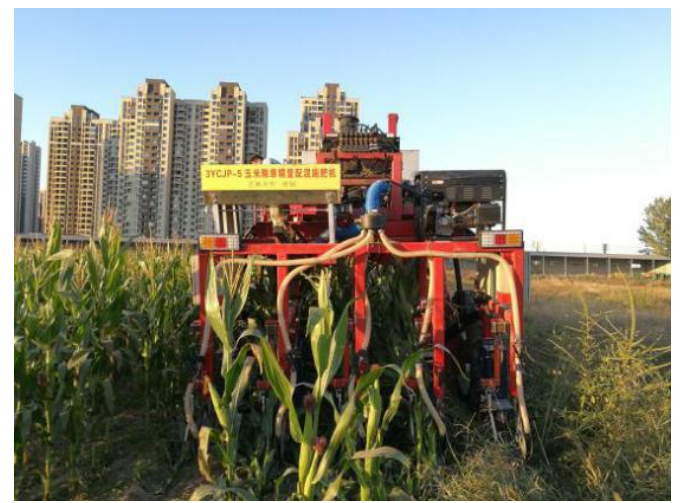

a. Field photos of complete machine

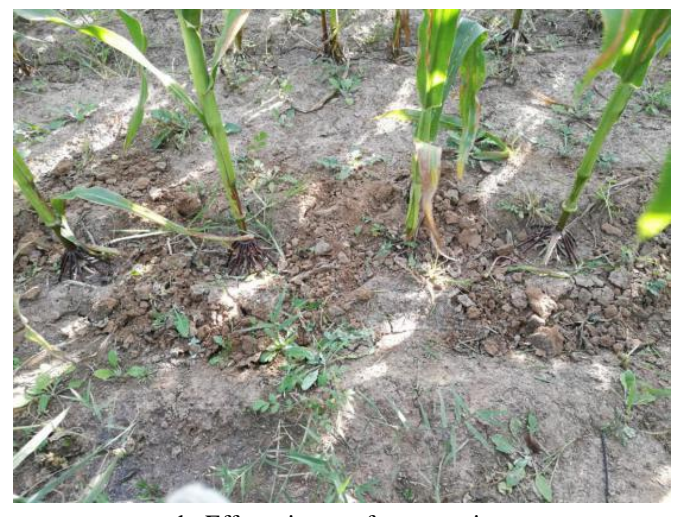

b. Effect picture after operation

Figure 8 Field operation performance test

Table 1 Test factors and levels of weeding actuator

\begin{tabular}{lcccc}
\hline \multicolumn{1}{c}{ Test factor } & \multicolumn{5}{c}{ Test level } \\
\cline { 3 - 6 } Bevel tool speed/r. $\mathrm{min}^{-1}$ & 800 & 1000 & 1200 & 1400 \\
Mechanism forward speed/km $\cdot \mathrm{h}^{-1}$ & 4 & 5 & 6 & 7 \\
Bevel tool depth in soil/cm & 2 & 6 & 10 & 14 \\
\hline
\end{tabular}

\subsection{Experimental indexes}

In the experiment, when the weeds were uprooted from the soil, the weeds were considered to be successfully eradicated, and the weeding rate was counted according to Equation (20). When the weeding unit touched the maize plant, the maize seedling was considered accidentally damaged. Whether the seedlings can survive or not, the seedling damage rate was counted according to Equation (21).

$$
\begin{aligned}
& \alpha=\frac{\beta}{\theta} \times 100 \% \\
& \gamma=\frac{\mu}{\eta} \times 100 \%
\end{aligned}
$$

where, $\alpha$ is the weeding rate, $\% ; \beta$ is the number of weeds cut out of the surface by the bevel tool; $\theta$ is the total number of weeds. The total number of weeds between plants was defined as the unearthed center of maize seedling as the center, and the width of left and right sides was set to $2 \mathrm{~cm}$ as the seedling belt to calculate the total number of weeds between plants; $\gamma$ is the seedling damage rate, $\%$; $\mu$ is damaged seedling and buried seedlings after the experiment; $\eta$ is the total number of maize plants before the experiment.

\subsection{Test results and analysis}

Table 2 and Table 3 show that the bevel tool speed and the bevel tool depth in soil have significant effects on the rates of weeding and seedling damage. The mechanism forward speed has an insignificant effect on the rates of weeding and seedling damage.

\begin{tabular}{|c|c|c|c|c|c|}
\hline \multirow{2}{*}{$\begin{array}{c}\text { Test } \\
\text { number }\end{array}$} & \multicolumn{3}{|c|}{ Test factor } & \multicolumn{2}{|c|}{ Test indicator } \\
\hline & $R / \mathrm{r} \cdot \min ^{-1}$ & $\mathrm{~S} / \mathrm{km} \cdot \mathrm{h}^{-1}$ & $T / \mathrm{cm}$ & $\begin{array}{l}\text { Weeding } \\
\text { rate } / \%\end{array}$ & $\begin{array}{c}\text { Seedling damage } \\
\text { rate } / \%\end{array}$ \\
\hline 1 & 800 & 4 & 2 & 91.4 & 2.7 \\
\hline 2 & 800 & 5 & 6 & 84.2 & 2.9 \\
\hline 3 & 800 & 6 & 10 & 82.7 & 2.4 \\
\hline 4 & 800 & 7 & 14 & 92.5 & 2.4 \\
\hline 5 & 1000 & 4 & 6 & 84.2 & 1.7 \\
\hline 6 & 1000 & 5 & 2 & 92.4 & 1.9 \\
\hline 7 & 1000 & 6 & 14 & 93.7 & 1.3 \\
\hline 8 & 1000 & 7 & 10 & 94.4 & 1.2 \\
\hline 9 & 1200 & 4 & 10 & 87.2 & 1.1 \\
\hline 10 & 1200 & 5 & 14 & 94.8 & 0.4 \\
\hline 11 & 1200 & 6 & 2 & 94.5 & 0.9 \\
\hline 12 & 1200 & 7 & 6 & 85.7 & 1.2 \\
\hline 13 & 1400 & 4 & 14 & 95.4 & 0.5 \\
\hline 14 & 1400 & 5 & 10 & 96.2 & 0.4 \\
\hline 15 & 1400 & 6 & 6 & 94.4 & 0.7 \\
\hline 16 & 1400 & 7 & 2 & 98.5 & 0.5 \\
\hline
\end{tabular}

Table 2 Orthogonal test of weeding actuator

Note: $R$ means the bevel tool speed; $S$ means the mechanism forward speed; $T$ means the bevel tool depth in soil, the same as below.

\begin{tabular}{|c|c|c|c|c|c|c|}
\hline Indicator & $\begin{array}{c}\text { Source of } \\
\text { Variance }\end{array}$ & $\begin{array}{l}\text { Sum of } \\
\text { Squares }\end{array}$ & $\begin{array}{c}\text { Degree of } \\
\text { Freedom }\end{array}$ & $\begin{array}{l}\text { Mean sum } \\
\text { of square }\end{array}$ & $F$ & Significance \\
\hline \multirow{5}{*}{$\begin{array}{c}\text { Weeding } \\
\text { rate }\end{array}$} & Intercept & 133626.803 & 1 & 133626.803 & 22084.033 & $0.000^{* *}$ \\
\hline & $R$ & 176.028 & 3 & 58.676 & 9.697 & $0.010^{*}$ \\
\hline & $S$ & 6.132 & 3 & 2.044 & 0.338 & 0.799 \\
\hline & $T$ & 147.153 & 3 & 49.051 & 8.106 & 0.016 \\
\hline & Error & 36.305 & 6 & 6.051 & & \\
\hline \multirow{5}{*}{$\begin{array}{l}\text { Seedling } \\
\text { damage } \\
\text { rate }\end{array}$} & Intercept & 29.976 & 1 & 29.976 & 1209.101 & $0.000^{* *}$ \\
\hline & $R$ & 0.697 & 3 & 0.232 & 9.370 & $0.011^{*}$ \\
\hline & $S$ & 0.277 & 3 & 0.092 & 3.723 & 0.080 \\
\hline & $T$ & 9.172 & 3 & 3.057 & 123.319 & $0.000^{* *}$ \\
\hline & Error & 0.149 & 6 & 0.025 & & \\
\hline
\end{tabular}

Table 3 Orthogonal test analysis of weeding actuator

Primary and secondary factors for weeding rate were bevel tool speed, bevel tool depth in soil and mechanism forward speed in a descending order. The optimal combination for weeding rate was that bevel tool speed of $1400 \mathrm{r} / \mathrm{min}$, mechanism forward speed of 7 $\mathrm{km} / \mathrm{h}$, bevel tool depth in soil of $2 \mathrm{~cm}$. Primary and secondary factors for seedling damage rate were bevel tool speed, bevel tool depth in soil and mechanism forward speed in a descending order. The optimal combination of seedling damage rate was that bevel tool speed of $1400 \mathrm{r} / \mathrm{min}$, mechanism forward speed of $7 \mathrm{~km} / \mathrm{h}$, bevel tool depth in soil of $14 \mathrm{~cm}$. It is considered that the deeper the depth in soil is, the more thorough the root system of weeds can be removed. Bevel tool speed of $1400 \mathrm{r} / \mathrm{min}$, machine forward speed of $7 \mathrm{~km} / \mathrm{h}$, and bevel tool depth in soil of $10 \mathrm{~cm}$ are considered as the comprehensive optimal combination. 
Due to the large variation of maize planting spacing in the experimental field, both the recognition accuracy and the motion trajectory of the weeding actuator were affected, thus affecting the actual operation effect. Since the optimal combination was not included in the experiment optimization design, three verification experiments were carried out according to the optimal combination, and the results showed that obtained that the average weeding rate was $95.8 \%$ and the average seedling damage rate was $0.6 \%$ under the optimal combination.

From the results of variance analysis and orthogonal test results, it can be seen that the weeding rate increases with the increase of the bevel tool speed. It is because, at high speed, the tool can produce greater cutting force, so as to effectively cut weeds. The result is consistent with the research conclusions of Han et $\mathrm{al}^{[23]}$. Since weeds belong to wild plants, sliding cutting has little influence on the cutting effect of weed species, but it has influence on the growth effect after cutting ${ }^{[24]}$.

In this study, the spiral structure was adopted to cut weeds. Compared with the comb type of $\mathrm{Li}^{[25]}$, this study used a bevel tool, which can effectively enter the soil and reduce the entanglement of weeds. Besides, the weeding rate increased with the increase of planting spacing. Because of the curved sliding cutting structure, the success rate of weeding was increased in contrast to the study of Peruzzi et al. ${ }^{[12]}$

Compared with cam structure in the research of Zhou et al. ${ }^{[26]}$ this study adopted intra-row spiral weeding method, which can eliminate weeds in a larger range and improve the weeding rate. Related studies show that in paddy fields, the deeper the weeding executive component penetrates into the soil, the higher the seedling damage rate is ${ }^{[27,28]}$. In this study, a higher depth has been selected, and it was found that when the soil penetration reaches a certain depth. There were insignificant effects on weeding rate and seedling damage rate. The reason was that the root length of weeds was generally about $10 \mathrm{~cm}$, and when the entering depth in soil reached $10 \mathrm{~cm}$, weeds could be basically removed.

In this study, an infrared beam tube was used to identify maize plants. Compared with the traditional trigger device, it is a non-contact sensor that can enhance reaction efficiency. However, due to the interference of maize leaves, the recognition rate of maize plants by the sensor was reduced, and damage may be caused to the seedlings.

According to the procedure set, the bevel tool should not be able to touch the roots of the maize stalks originally. However, due to the great entering bevel tool depth in soil, resistance was generated in rotation movement ${ }^{[29]}$. During the advancement of the machine, maybe the bevel tool rotation is not in place or in time, resulting in high seedling damage rates. In addition, the distance of intra-row planting spacing is too small, which may cause the machine to injure the plant.

\section{Conclusions}

1) A weeding actuator was designed, which identified plants by infrared beam sensor and spirally advanced amid maize plants.

2) The sliding cutting curve was used to cut weeds. Due to the shear force generated when cutting weeds, the power consumption was reduced.

3) Through the SPSS design analysis test, it was concluded that the primary and secondary factors that affecting the weeding rate and seedling damage rate were bevel tool speed, bevel tool depth in soil and mechanism forward speed in a descending order. The optimal combination was obtained as the bevel tool speed of $1400 \mathrm{r} / \mathrm{min}$, machine forward speed of $7 \mathrm{~km} / \mathrm{h}$, and bevel tool depth entering in soil of $10 \mathrm{~cm}$. Under the optimal combination, the average weeding rate was $95.8 \%$ and the average seedling damage rate was $0.6 \%$.

\section{Acknowledgements}

This work was financially supported by the National Natural Science Foundation of China (Grant No. 31901408).

\section{[References]}

[1] Du Z L, Angers D A, Ren T S, Zhang Q Z, Li G C. The effect of no-till on organic $\mathrm{C}$ storage in Chinese soils should not be overemphasized: A meta-analysis. Agriculture, Ecosystems \& Environment, 2017; 236: $1-11$.

[2] Jia H, Wang G, Guo L, Zhuang J, Tang L. Wind erosion control utilizing standing corn residue in Northeast China. Soil \& Tillage Research, 2015; 153: $112-119$.

[3] Kouwenhoven J K. Intra-row mechanical weed control possibilities and problems. Soil \& Tillage Research, 1997; 41(1): 87-104.

[4] Lian Q, Tan F, Fu X M, Zhang P, Liu X, Zhang W. Design of precision variable-rate spray system for unmanned aerial vehicle using automatic control method. Int J Agric \& Biol Eng, 2019; 12(2): 29-35.

[5] Melander B, Jabran K, De Notaris C, Znova L, Green O. Inter-row hoeing for weed control in organic spring cereals-influence of inter-row spacing and nitrogen rate. European Journal of Agronomy, 2018; 101: 49-56.

[6] Melander B. Optimization of the adjustment of a vertical axis rotary brush weeder for intra-row weed control in row crops. Journal of Agricultural Engineering Research, 1997; 68(1): 39-50.

[7] Fogelberg F, Kritz G. Intra-row weeding with brushes on vertical axes factors influencing in-row soil height. Soil \& Tillage Research, 1999; 50(2): 149-157.

[8] Tian L, Cao C M, Qin K, Fang L F, Ge J. Design and test of post-seat weeding machine for paddy. Int $\mathrm{J}$ Agric \& Biol Eng, 2021; 14(3): $112-122$.

[9] Chen Z W, Li N, Sun Z, Li T, Zhang CL, Li W. Optimization and experiment of intra-row brush weeding manipulator based on planetary gear train. Transactions of the CSAM, 2015; 46(9): 94-99. (in Chinese)

[10] Jia H L, Li S S, Wang G, Liu H L. Design and experiment of seedling avoidable weeding control device for intertillage maize. Transactions of the CSAM, 2018; 34(7): 15-22. (in Chinese)

[11] Pannacci E, Tei F, Guiducci M. Mechanical weed control in organic winter wheat. Italian Journal of Agronomy, 2017; 12(4): 336-342.

[12] Peruzzi A, Martelloni L, Frasconi C, Fontanelli M, Firchio M, Raffaelli M. Machines for non-chemical intra-row weed control in narrow and wide-row crops: a review. Journal of Agricultural Engineering, 2017; 48(2): 583. doi: 10.4081/jae.2017.583.

[13] Cordill C, Grift T E. Design and testing of an intra-row mechanical weeding machine for corn. Biosystems Engineering, 2011; 110(3): 247-252.

[14] Xie C Q, Yang C, Hummel Jr A, Johnson G A, Izuno F T. Spectral reflectance response to nitrogen fertilization in field grown corn. Int $\mathrm{J}$ Agric \& Biol Eng, 2018; 11(4): 118-126.

[15] Blasco J, Aleixos N, Roger J M, Rabatel G, Molto E. Robotic weed control using machine vision. Biosystems Engineering, 2002; 83(2): $149-157$.

[16] Zhou F J, Wang W M, Li X L, Tang Z F. Design and experiment of the cam rocker swing intra-row weeding device for maize. Transactions of the CSAM, 2017, 49(1): 77-85. (in Chinese)

[17] Han B, Guo C, Gao Y L, Liu Q, Sun S, Dong X W. Design and experiment of soybean intra-row weeding monomer mechanism and key components. Transactions of the CSAM, 2020; 51(6): 112-121. (in Chinese)

[18] Niu C L, Wang J W. Paddy strains between weeding member working mechanism and weeding track test. Journal of Agricultural Mechanization Research, 2017; 39(1): 177-181. (in Chinese)

[19] Gobor Z. Mechatronic system for mechanical weed control of the intra-row area in row crops. KI-Künstliche Intelligenz, 2013; 27(4): 379-383.

[20] Wang C, Li Z W. Weed recognition using SVM model with fusion height 
and monocular image features. Transactions of the CSAE, 2016; 32(15): 165-174. (in Chinese)

[21] Jia H L, Wang G, Guo M Z, Shah D, Jiang X M, Zhao J L. Methods and experiments of obtaining corn population based on machine vision. Transactions of the CSAM, 2015; 31(3): 215-220. (in Chinese)

[22] Wang Y X, Osman A N, Zhang D X, Yang L, Cui T, Zhong X J. Optimized design and field experiment of a staggered vibrating subsoiler for conservation tillage. Int J Agric \& Biol Eng, 2019; 12(1): 59-65.

[23] Han B, Shen J Y, Li Y M. Design and experiment of 3ZCF-7700 multi-functional weeding-cultivating machine. Transactions of the CSAM, 2011; 27(1): 124-129. (in Chinese)

[24] Christian A, Camilla H, Charlotte M, Nina K. Regrowth of weed species after cutting. Weed Technology. 2002; 16(4): 873-879.

[25] Li S S. Design and experiment of seedling avoidable weeding control device for intertillage maize. Master dissertation. Changchun, China: Jilin University, 2015; 79p.

[26] Wang J F, Wang J W, Yan D W, Tan H, Zhou W Q. Design and experiment of $3 \mathrm{scj}-2$ type row weeding machine for paddy field. Transactions of the CSAM, 2017; 48(6): 71-78. (in Chinese)

[27] Zhang C L, Chen L Q, Xia J F, Zhang J M. Effects of blade sliding cutting angles and stem level on cutting energy of rice stems. Int J Agric \& Biol Eng, 2019; 12(6): 75-81.

[28] Chen F E, Liang X M, Chen L H, Liu B Y, Lan Y B. Novel method for real-time detection and tracking of pig body and its different parts. Int $\mathbf{J}$ Agric \& Biol Eng, 2020; 13(6): 144-149.

[29] Melander B, Lattanzi B, Pannacci E. Intelligent versus non-intelligent mechanical intra-row weed control in transplanted onion and cabbage. Crop Protection, 2015; 72: 1-8. 